The INL is a

U.S. Department of Energy

National Laboratory

operated by

Battelle Energy Alliance

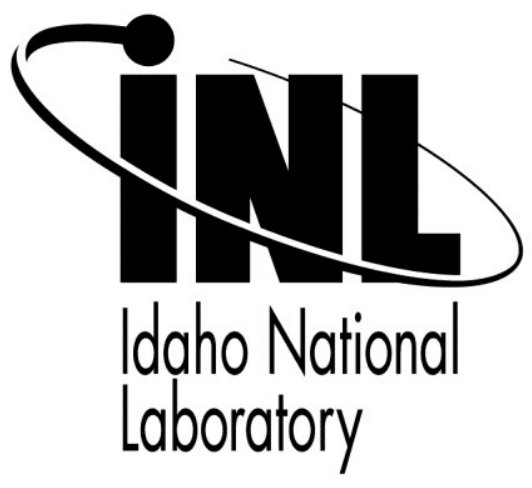

\title{
Extraction Behavior of Selected Rare Earth Metals from Acidic Chloride Media Using Tetrabutyl Diglycolamide
}

M.E. Case, R.V. Fox

D.L. Baek, B.J. Mincher

(Idaho National Laboratory)

C.M. Wai

(University of Idaho)

\section{April 2017}

This is an accepted manuscript of a paper intended for publication in a journal. This document was prepared as an account of work sponsored by an agency of the United States Government. Neither the United States Government nor any agency thereof, or any of their employees, makes any warranty, expressed or implied, or assumes any legal liability or responsibility for any third party's use, or the results of such use, of any information, apparatus, product or process disclosed in this report, or represents that its use by such third party would not infringe privately owned rights. The views expressed in this paper are not necessarily those of the United States Government or the sponsoring agency.

Prepared for the U.S. Department of Energy Office of Nuclear Energy

Under DOE Idaho Operations Office Contract DE-AC07-05ID14517 



\section{Extraction Behavior of Selected Rare Earth Metals from Acidic Chloride \\ 2 Media Using Tetrabutyl Diglycolamide}

\section{3 (Extraction of Select REEs from Chloride Media Using TBDGA)}

4 Case, M.E. ${ }^{\mathrm{a}, \mathrm{b}}$; Fox, R.V.'; Baek, D.L. ${ }^{\mathrm{a}}$; Mincher, B.J. ${ }^{\mathrm{a}}$; Wai, C.M. ${ }^{\text {b }}$

5 addaho National Laboratory, 2525 Fremont Ave, Idaho Falls, ID 83402

6 bUniversity of Idaho, 709 S Deakin St, Moscow, ID 83844

7 Corresponding author: E-mail address: mary.case@inl.gov (M. E. Case)

9 Key words: Rare earth elements; solvent extraction; lanthanides; diglycolamides; extraction; 10 chloride

11 Abstract

Rare earth elements (REEs) are vital to modern, high-tech devices. Recycling REEs

13 from post-consumer electronics can potentially diminish supply chain risks. Toward that end,

14 liquid-liquid solvent extraction of various REEs was investigated with tetrabutyl diglycolamide

15 (TBDGA) in 1-octanol from hydrochloric acid media. Metal partitioning to the organic phase

16 was shown to increase as $\left[\mathrm{Cl}^{-}\right]$increased. In contrast, increasing $\left[\mathrm{H}^{+}\right]$did not improve extraction.

17 The use of the polar diluent 1-octanol provided high extraction efficiency, especially for the

18 partition of heavy lanthanides from solutions of high chloride concentration. Although the polar

19 diluent also extracted molar amounts of water and acid, it was concluded that a neutral 
metal/TBDGA complex as mainly the di-solvate was extracted, and that complexation was

21 observed to be exothermic. These results indicate that REE extraction from aqueous chloride

22 solutions can be efficient without the use of high acid concentrations.

\section{Introduction}

24 Rare earth elements are industrially important due to their appearance in energy-efficient 25 electronic devices, magnets, lighting phosphors, solid-oxide fuel cells, catalysts, and advanced 26 weapons systems. ${ }^{[1-4]}$ Rare earth elements include the 15 elements in the lanthanide series plus

27 scandium, and yttrium. Beginning in the mid-1980s rare earth ore production in southern China

28 began to eclipse production from all other countries around the world. ${ }^{[2]}$ Due to the internal

29 policies in China, production of rare earth-laden ores and refined products was heavily

30 subsidized, driving other global suppliers from the marketplace. In 2010, China produced $>95 \%$

31 of the world supply of lanthanide ores and refined rare earth products. ${ }^{[5]}$ As the electrification of

32 society advances and high tech devices continue to be deployed into the world market, the need

33 for "technology metals" will increase accordingly. Artificial materials shortages created by a

34 single country that monopolizes supply could potentially have a significant negative effect

35 world-wide on high-tech industrial sectors that rely heavily on rare earth materials.

To address potential rare earth materials supply challenges recycling strategies for recovery

37 of critical materials have been proposed as a key component of a multi-faceted sustainability

38 approach. An important step in the recycle/recovery process is the use of hydrometallurgical

39 technologies for the recovery of rare earth materials from various streams (e.g., manufacturing

40 scrap, end-of-life electronics, spent catalysts, etc). Kronholm et al. ${ }^{[6]}$ recently published a primer

41 on the essential aspects of hydrometallurgical processes for rare earth separations. Others have 
42 recently contributed to advancing the current state of hydrometallurgical technologies for

43 recovering rare earths from consumer electronics, end-of-life products, and industrial waste

44 containing rare earths. ${ }^{[7-16]}$ The basic hydrometallurgical approach is to render an insoluble, solid

45 form of the targeted metal into an aqueous soluble form by use of strong mineral acids. Once

46 dissolved, ionic metal species are then extracted to an organic diluent phase via use of metal

47 complexing agents. Metal is then commonly recovered from the organic phase through acid

48 stripping, or back extraction into an aqueous acidic solution. Selection of the acid used for

49 dissolution, and the ligand used for forming the organic soluble metal-ligand complex at the

50 front-end of the hydrometallurgical process, can have profound effects on downstream

51 separations and overall process efficiency and economics. Some matrices are highly recalcitrant,

52 are not successfully attacked by nitric acid alone (e.g., phosphors, ores, catalysts), and require

53 use of $\mathrm{HCl}$ to accomplish dissolution. It should also be noted that modern, industrial-scale

54 chemistry used to leach and recover lanthanides from REE-rich ores is chloride-based. ${ }^{[17]}$

55 Recently, diglycolamide ligands (DGAs) have shown superior extraction properties for rare

56 earth elements with the added advantage of the ligand being incinerable, ${ }^{[18-19]}$ which is a

57 problematic issue with regards to organophosphorus ligands. For example, our group previously

58 reported data concerning the extraction of lanthanides and americium using tetrabutyl

59 diglycolamide (TBDGA)/ 1 -octanol extraction from $\mathrm{HNO}_{3}$ solution. ${ }^{[20]}$ Others have recently

60 reported that DGAs have stated advantages for separations from $\mathrm{HCl}$ including improved

61 separation factors between light and heavy lanthanides, ${ }^{[17-19,21]}$ exothermic complex formation

62 reactions in a variety of diluent systems, ${ }^{[17,19,21]}$ improved recovery of lanthanides from mixed

63 metal liquors that contain high concentrations of transition metals (e.g., Fe, Ni, Co), ${ }^{[21]}$ and even

64 synergistic enhancement of lanthanide extraction in the presence of transition metals. ${ }^{\text {[22] }}$ 
Therefore, in this study we examine the extraction behavior of select rare earth metal ions

66 from chloride media using the digylcolamide ligand, TBDGA. The structure of TBDGA is

67 shown in Figure 1. Liquid-liquid solvent extraction was performed with TBDGA in 1-octanol as

68 the diluent. Pure 1 -octanol was chosen to provide the highest possible lanthanide extraction

69 efficiency, given that polar diluents have been reported to provide high extraction efficiency as

70 compared to the less polar but traditional dodecane/octanol mixtures. ${ }^{[23]}$ The effects of $\left[\mathrm{H}^{+}\right],\left[\mathrm{Cl}^{-}\right.$

71 ], [TBDGA], temperature, and equilibration time on extraction of various rare earth elements

72 from chloride media were examined. Previous work has shown the effects of [HCl], [TBDGA],

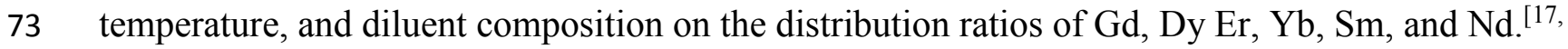

$74{ }^{19]}$ Work performed here expands the body of literature by studying additional REEs for which

75 there are currently no data, by demonstrating the effects of varying $\left[\mathrm{Cl}^{-}\right]$at constant $\left[\mathrm{H}^{+}\right]$, and by

76 use of 1-octanol as a diluent.

77 Materials and Methods

All liquid-liquid extractions were performed in $15 \mathrm{~mL}$ Corning conical tubes using equal

79 volume contacts of the acid-pre-equilibrated organic phase with a metal loaded aqueous phase of

80 the appropriate acid concentration. Removal of separated phases was performed with $2 \mathrm{~mL}$ glass

81 Pasteur pipettes. A Centrific model 228 (Fisher Scientific, Hampton, NH) centrifuge was used to

82 aid in phase separation. All ICP-MS analyses were performed on an Agilent model 7900 ICP-

83 MS (Agilent, Santa Clara, CA). The following reagents from Sigma-Aldrich (Sigma-Aldrich, St.

84 Louis, MO) were used as-received: hydrochloric acid (ACS grade), 1-octanol ( $\geq 99 \%$ ), yttrium

85 (III) chloride hexahydrate (99.9\%), cerium (III) chloride heptahydrate $(99.9 \%)$, neodymium (III)

86 chloride hexahydrate (99.99\%), samarium (III) chloride hexahydrate ( $\geq 99 \%$ ), europium (III)

87 chloride hexahydrate (99.99\%), terbium (III) chloride hexahydrate (99.9\%), dysprosium (III) 
chloride hexahydrate (99.9\%), holmium (III) chloride hexahydrate (99.9\%), lutetium (III) chloride hexahydrate (99.9\%). Lanthanum (III) chloride heptahydrate (99.7\%) was used asreceived from J.T. Baker Chemical Company (J.T. Baker, Center Valley, PA). $\mathrm{NaCl}(\geq 99 \%)$ was used as-received from GFS Chemicals (GFS Chemicals, Powell, OH). N,N,N',N'tetrabutyldiglycolamide (95\%) (TBDGA) was used as-received from Tractus Chemical (Tractus Chemical, London, England).

All aqueous solutions were prepared with water purified to a resistivity of at least 18 $\mathrm{M} \Omega-\mathrm{cm}^{-1}$. The concentration of the REEs in the aqueous phase was determined by ICP-MS. Since it was not possible to perform ICP-MS on the organic phase using existing equipment, the concentration of the REEs in the organic phase was determined by the difference between the original aqueous solution concentration ([Ln] $\left.]_{\text {init }}\right)$ and the concentration in the final aqueous phase ([Ln $\left.]_{\text {post }}\right)$. Because the organic phase concentration was determined by difference, no mass balance analysis was possible. The distribution ratio $\left(D_{\mathrm{Ln}}\right)$ was calculated using eq. 1 where the concentration of metal determined in the organic phase, $\left([\mathrm{Ln}]_{\text {init }}-[\mathrm{Ln}]_{\text {post }}\right)$, was divided by the concentration of metal in the aqueous phase, $[\mathrm{Ln}]_{\text {post. }}$ An element is considered extracted with a $D_{\text {Ln }}$ of one or greater.

$$
D_{\mathrm{Ln}}=\frac{[L n]_{\text {init }}-[L n]_{\mathrm{post}}}{[L n]_{\mathrm{post}}}
$$

To ensure that equilibrium distribution ratios were being measured, $8.0 \mathrm{M} \mathrm{HCl}$ preequilibrated $10 \mathrm{mM}$ TBDGA/1-octanol was used to contact $8 \mathrm{M} \mathrm{HCl}$ containing about $100 \mathrm{ppb}$ Y, La, Ce, Nd, Sm, Eu, Tb, Dy, Ho, and Lu added as chloride salts for contact times of 5, 10, 30, and 60 minutes. After the specified contact time the solution was centrifuged for 5 minutes and the aqueous phase was removed. The distribution ratios for the various contact times were then 
110 determined by the same method as above. These results indicated that the contact time of 15

111 minutes used in all the experiments in this study provided equilibrium $D_{\text {Ln }}$ values. All contacts

112 were performed at a temperature of $22 \pm 1{ }^{\circ} \mathrm{C}$.

Water concentrations were determined by duplicate Karl Fisher titration measurements

114 for each extraction sample with a Metrohm 899 Coulometer (Metrohm USA, Riverview, FL). A

115 sample size of $0.1 \pm 0.02 \mathrm{~g}$ of the organic was used.

Acidity concentrations were determined by acid/base titration. One milliliter of the

117 organic sample was contacted for 5 minutes with $5 \mathrm{~mL}$ of nanopure water. After centrifuging for 1185 minutes the aqueous phase was collected. This was repeated for 5 total washes. The collected 119 aqueous was diluted to about $100 \mathrm{~mL}$ and 2 drops of a phenolphthalein indicator (Idaho National 120 Laboratory, Idaho Falls, ID) was added. This solution was titrated with $0.01 \mathrm{M}$ standardized

$121 \mathrm{NaOH}$ (Fisher Scientific, Hampton, NH) in a class A buret. This analysis was performed in 122 triplicate for each sample.

\section{Results and Discussion}

\section{Extraction Behavior as a Function of Ionic Radii}

Plotting ionic radii $\mathrm{CN}=6,{ }^{[24]}$ versus the distribution ratio, Figure 2, shows the general trend for the extraction of REEs with TBDGA from 8.0 M HCl. Overall, the relationship

127 between ionic radii and $D_{\mathrm{Ln}}$ is inversely proportional. As the ionic radii increase the $D_{\mathrm{Ln}}$ 128 decrease, suggesting the expected trend of lanthanide ions of higher charge density being better 129 complexed and extracted. The overall trend agrees with that observed by Cui et al., with TBDGA 130 extraction from $\mathrm{HCl}$ using various diluents other than 1 -octanol. ${ }^{[17]}$ Similar results have been 
131 reported for TODGA/dodecane extractions of both lanthanides and actinides by Sasaki et al., ${ }^{[25]}$

132 This also is consistent with our previous report for the extraction of lanthanides from $\mathrm{HNO}_{3}$

133 using TBDGA/1-octanol. ${ }^{[20]}$ This $\mathrm{HNO}_{3}$ data is shown along with our new $\mathrm{HCl}$ data in Figure 2,

134 for comparison. The light lanthanides show better extraction behavior from $\mathrm{HCl}$; the heaviest 135 lanthanides Ho and Lu have high extraction efficiency from both acids. The better extraction of 136 metals from $\mathrm{HCl}$ is in agreement with the Hofmeister "salting out" series for the extraction of a 137 neutral species. ${ }^{[26]}$

\section{Effect of Varying [HCl]}

Data for the extraction of lanthanides from 1.0 $\mathrm{M}$ to $8.0 \mathrm{M} \mathrm{HCl}$ using pre-equilibrated 10 mM TBDGA/1-octanol are graphically depicted in Figure 3. For all rare earths tested, as [HCl]

141 increased in the aqueous phase the amount of REE extracted into the organic phase also increased. This trend was also observed by Cui et al., ${ }^{[17,19]}$ for TBDGA extraction from $\mathrm{HCl}$ using several other diluents. An element is considered extractable for process application if the 144 distribution ratio, $D_{\mathrm{Ln}}$, is greater than one. From 0.1 to $1.0 \mathrm{M} \mathrm{HCl}$ none of the REEs examined were extractable. From $>3.0 \mathrm{M} \mathrm{HCl}, \mathrm{Y}, \mathrm{Tb}, \mathrm{Dy}, \mathrm{Ho}$, and Lu were extractable with $D_{\mathrm{Ln}}$ in the

146 range of 1.5 to 4.1 . All other elements were poorly extracted with $D_{\operatorname{Ln}}<1$. As the acid 147 concentration was further increased, the heavy lanthanides Dy, Ho, and Lu, became highly 148 extractable from $5.0 \mathrm{M} \mathrm{HCl}$, with $D_{\mathrm{Ln}}$ in the range 10.8 to 18.8. Samarium, Eu, Tb, and Y were 149 also extractable with lower $D_{\text {Ln }}$ in the range of 2.0 to 7.4. Lanthanum, Ce, and $\mathrm{Nd}$ were still 150 poorly extracted with $D_{\mathrm{Ln}}<1$. Finally, from $8.0 \mathrm{M} \mathrm{HCl}$ only the light lanthanides, La and Ce, 151 remained poorly extracted with $D_{\mathrm{Ln}}<1$. Neodymium and Sm were extractable with $D_{\mathrm{Ln}}$ in the 152 range 2.0 to 9.0. All other REEs examined were highly extractable from highly acidic solution 153 with $D_{\text {Ln }}$ in the range of 15.1 to 142 . Thus, a separation of the REEs into light and heavy 
154 fractions can be envisioned under these conditions. Increasing extraction efficiency with

155 increasing $[\mathrm{HCl}]$ is consistent with the requirement for charge neutralization of a metal complex

156 by $\mathrm{Cl}^{-}$anion prior to extraction. To separate the effect of acidity from $\left[\mathrm{Cl}^{-}\right]$, extraction at varying

$157\left[\mathrm{Cl}^{-}\right]$with constant $[\mathrm{HCl}]$ was next performed.

Effect of Varying [Cl]

159 Figure 4 shows the distribution ratios of REEs into an organic phase containing $10 \mathrm{mM}$

160 TBDGA/ 1 -octanol from an aqueous phase containing $1.0 \mathrm{M} \mathrm{HCl}$ and varying $\left[\mathrm{Cl}^{-}\right]$ranging from

$1612.0 \mathrm{M}$ to $4.0 \mathrm{M}$, added as $\mathrm{NaCl}$ (total $\mathrm{Cl}^{-}$range $3.0 \mathrm{M}$ to $5.0 \mathrm{M}$ ). A similar trend was observed as

162 was seen in the previous experiment where $[\mathrm{HCl}]$ was varied. However, for these experiments,

163 when $\left[\mathrm{H}^{+}\right]$was kept constant and $\left[\mathrm{Cl}^{-}\right]$was varied, the magnitude of increase in $D_{\text {Ln }}$ was greater

164 for neutral $\mathrm{Cl}^{-}$. This indicates that $\left[\mathrm{H}^{+}\right]$can actually have a deleterious effect on metal extraction.

165 This suggests that $\mathrm{HCl}$ competes for the ligand and that in this polar alcoholic diluent the amount

166 of $\mathrm{HCl}$ extracted by TODGA is sufficient to interfere with lanthanide metal ion extraction.

167 Further evidence of the adverse effect of acidity on extraction is shown in Figure 5. The

168 distribution ratios of different REEs from aqueous phases containing $0 \mathrm{M}, 1.0 \mathrm{M}$, and $5.0 \mathrm{M}\left[\mathrm{H}^{+}\right]$

169 where $\left[\mathrm{Cl}^{-}\right]$is held constant at $5.0 \mathrm{M}$ are given. Distribution ratios are shown as 100 for elements

170 that were below detection limit for the ICP-MS analysis of the aqueous phase indicating that

171 almost all of the metal was extracted into the organic phase. It can be seen that for a constant

172 chloride concentration, increasing acidity greatly decreased the $D_{\text {Ln }}$ values, indicating again that

$173 \mathrm{HCl}$ has a negative effect on the extraction of REE into the organic phase. By reducing [ $\mathrm{HCl}]$ to

$1741.0 \mathrm{M}$, but keeping $\left[\mathrm{Cl}^{-}\right]$at $5.0 \mathrm{M}$ the $D_{\mathrm{Ln}}$ is increased by about $3.5 \mathrm{x}$ for most of the REEs. When

175 there was no $\mathrm{HCl}$ in the aqueous solution, but the $\mathrm{Cl}^{-}$was constant at $5.0 \mathrm{M}$, the $D_{\mathrm{Ln}}$ increased 
176 about $2 \mathrm{x}$ to $9 \mathrm{x}$ when compared to the solution with $1.0 \mathrm{M} \mathrm{HCl}$. These results introduce the

177 concept that for potential process applications $[\mathrm{HCl}]$ may be kept at a minimum and $D_{\mathrm{Ln}}$ for

178 different REEs can be optimized by varying $\left[\mathrm{Cl}^{-}\right]$through use of a less expensive source of $\mathrm{Cl}^{-}$,

179 e.g., $\mathrm{NaCl}$.

If the extracted complex is indeed neutral, as is usually assumed for extraction into non-

181 polar media, high $\left[\mathrm{Cl}^{-}\right]$facilitates extraction from aqueous media because the TBDGA metal

182 complex requires three $\mathrm{Cl}^{-}$to satisfy the metal ion charge. Equation 2 shows the complexation

183 that occurs to form a charge neutral species. The chloride ion poorly complexes with the metal

184 ions. $^{[17]}$ Thus, a high chloride concentration is needed to drive the equilibrium toward the neutral 185 species which is extractable into the organic phase.

$$
\mathrm{Ln}_{(\mathrm{aq})}^{3+}+n \mathrm{TBDGA}_{(\mathrm{o})}+3 \mathrm{Cl}_{(\mathrm{aq})}^{-} \leftrightarrow \mathrm{Ln}\left(\mathrm{TBDGA}_{n} \mathrm{Cl}_{3(\mathrm{o})}\right.
$$

187 A very polar diluent such as 1 -octanol can be assumed to extract acid and water, and thus

188 possibly some metal ions, perhaps even in the absence of the DGA. In that case, metal may be

189 extracted as species other than the neutral complex represented in Eq 2. This is discussed in more 190 detail in the next section.

\section{Extraction of acid and water by 1-octanol}

To evaluate the effects of the extraction of water and acid by the polar diluent and their

193 possible effect on metal extraction, Eu solutions of $\mathrm{HCl}$ or $\mathrm{NaCl}$ were contacted with 1-octanol

194 and the post-contact organic solutions were measured for their concentrations of water, $\mathrm{HCl}$ and

195 Eu. The acidity measured in post-contact 1 -octanol was below detection limit $(<\sim 0.01 \mathrm{M})$

196 following contact with pure water, or neutral $\mathrm{NaCl}$ solution, and only slightly elevated to 0.029 
$\mathrm{M}$ following contact with $0.5 \mathrm{M} \mathrm{HCl}$. However, the acid content of 1 -octanol after contact with 8 $\mathrm{M} \mathrm{HCl}$ was significant, at $2.15 \mathrm{M}\left(D_{\mathrm{HCl}}=0.37\right)$. These results are shown in Table 1. Geist ${ }^{[27]}$ reported the extraction of similar amounts of $\mathrm{HNO}_{3}$ by 1 -octanol. Also shown in Table 1 is that the extraction of water was significant in all cases, with approximately $3 \mathrm{M} \mathrm{H}_{2} \mathrm{O}$ in the organic

201 phase after contact with pure water, decreasing to $1.6 \mathrm{M}$ at higher neutral chloride

202 concentrations, consistent with the lower water concentration of very salty solutions. However, a 203 greater amount of water was extracted from the $8 \mathrm{M} \mathrm{HCl}$ solution, possibly due to the

204 equilibrium concentration of approximately $2 \mathrm{M} \mathrm{HCl}$ in that organic phase, creating a more polar 205 solution than pure octanol alone. Finally, Eu distribution ratios for extraction into ligand-free 1206 octanol are also shown in Table 1, where only the solutions containing measurable acid extracted 207 detectable Eu. However the $D_{\text {Eu }}$ was low regardless of the acid concentration and therefore 208 significant extraction of non-complexed metal cations can be ruled out even for polar 1-octanol. 209 This result provides greater confidence that neutral complexes such as that depicted in Eq. 2 are 210 the extracted metal species.

211 Table 1. Equilibrium organic-phase concentrations of water and acid, and the distribution ratio of 212 europium $\left(D_{\mathrm{Eu}}\right)$ into 1 -octanol following contact with various aqueous solutions.

\begin{tabular}{|l|l|l|l|}
\hline Solution Composition & Distribution Ratio $(\mathrm{Eu})$ & $\mathrm{H}_{2} \mathrm{O}(\mathrm{M})$ & {$\left[\mathrm{H}^{+}\right](\mathrm{M})$} \\
\hline Blank 1-octanol & Not measured & $0.02 \pm 0.0004$ & $<0.01$ \\
\hline $0 \mathrm{M} \mathrm{HCl}$-contacted & $<0.0002$ & $2.40 \pm 0.043$ & $<0.01$ \\
\hline $0.5 \mathrm{M} \mathrm{HCl}$-contacted & $0.14 \pm 0.07$ & $2.30 \pm 0.035$ & $0.029 \pm 0.001$ \\
\hline $8 \mathrm{M} \mathrm{HCl}$-contacted & $0.13 \pm 0.07$ & $6.89 \pm 0.055$ & $2.15 \pm 0.05$ \\
\hline $0.5 \mathrm{M} \mathrm{NaCl}$-contacted & $<0.006$ & $2.12 \pm 0.042$ & $<0.01$ \\
\hline $5 \mathrm{M} \mathrm{NaCl}$-contacted & $<0.004$ & $1.31 \pm 0.039$ & $<0.01$ \\
\hline
\end{tabular}


To further understand metal complex speciation in 1-octanol, slope analysis was used to

216

217

218

219

220

221

222

223

224

225

226

227

228

229

230

231

232

233

234

235

236 237 metal complex in a non-polar solvent. our Eu result for 1 -octanol. ${ }^{[23,24]}$

determine the number of TBDGA molecules, $n$, in the neutral metal-ligand complex (eq. 2 )

$\mathrm{M}(\mathrm{TBDGA})_{n} \mathrm{Cl}_{3}$. The value of $\mathrm{n}$ is determined as the slope of the plot of the log of the

distribution ratio $D_{M}$ versus the $\log$ of [TBDGA], Figure 6. From this analysis a slope of $2.13 \pm$

0.05 for $\mathrm{Eu}$ TBDGA/1-octanol extraction from $\mathrm{HCl}$ was determined, suggesting that the complex is a di-solvate mixed-ligand species, e.g., $\mathrm{Eu}(\mathrm{TBDGA})_{2} \mathrm{Cl}_{3}$. We previously reported a slightly higher value of $2.47 \pm 0.08$ for Eu extraction from $\mathrm{HNO}_{3}$ using TBDGA/1-octanol. ${ }^{[20]}$

Cui et al., ${ }^{[17]}$ reported stoichiometry for the extraction of Gd, Dy, Er, and $\mathrm{Yb}$ from $\mathrm{HCl}$ using TBDGA in several diluents. Their work indicated that mono-solvates were extracted into alkanes and $\mathrm{CCl}_{4}$, di-solvates were extracted into $\mathrm{CHCl}_{3}$, and that tri-solvates were extracted into toluene and 1-octanol/octane mixtures. This was attributed to an effect of diluent polarity, with the lower stoichiometry associated with the non-polar diluents. (However, it must be noted that toluene is only of moderate polarity, in contrast to that conclusion.) This is in contrast to the disolvate value reported in our work here for very polar 1 -octane as a diluent. As discussed below, most authors have reported higher L:M stoichiometry for polar diluents, which is consistent with

For example, based upon their similar ionic radii $\left(1.01 \AA\right.$ for $\mathrm{Am}^{3+}$ vs. $0.950 \AA$ for $\mathrm{Eu}^{3+}$, coordination number $=6$ ), ${ }^{[24]}$ it might be expected that Am extraction by DGAs would be similar to Eu. A comprehensive study of Am extraction from $\mathrm{HNO}_{3}$ by Sasaki et al., ${ }^{[29]}$ using several DGAs over a wide range of alkane chain lengths concluded that a higher number of ligand molecules were required to solvate the extracted complex for extraction into non-polar diluents. This is the expected result, since additional solvation should enhance solubility of the 

tetraoctyldiglycolamide (TODGA), in non-polar, long-chain alkane diluents. Wilden et al., ${ }^{[29]}$ reported almost identical stiochiometry of 2.68 and 2.73 for the TODGA extraction of Eu and Am into the non-polar, kerosene-like alkane mixture hydrogenated tetrapropene (TPH) from nitric acid. Similarly, Ravi et al., ${ }^{[28]}$ reported values for Am extraction using several

243 unsymmetrical DGAs in dodecane from nitric acid with an average stiochiometry of 2.83 \pm 0.04 .

244 The review by Ansari et al., ${ }^{[23]}$ concluded that polar diluents such as 1 -octanol required only two 245 TODGA molecules for solvation, while non-polar diluents such as dodecane required three to 246 four TODGA molecules. Thus, most authors have reported lower stiochiometry for DGA metal 247 complex extraction when using polar diluents. This is in agreement with our findings reported 248 above for Eu extraction using TBDGA/1-octanol. Finally, the effect of diluent polarity on the magnitude of the distribution ratio should be 250 considered. The effect of diluent on extraction of REEs from $\mathrm{HCl}$ with TBDGA was studied by 251 Cui et al. ${ }^{[17]}$ Those authors reported that the extraction efficiency increased with polarity of the 252 diluent, and when polar octanol was added to octane the extraction efficiency of the mixture 253 increased. They also reported that moderately polar toluene was an exception and provided low 254 distribution ratios under all conditions studied. Their distribution ratios for the extraction of Dy 255 with TBDGA from $\mathrm{HCl}$ for various diluents are depicted in Figure 7, along with our value for 1256 octanol, where it is seen that 1 -octanol provided the highest distribution ratios and fit the trend 257 reported by Cui et al. ${ }^{[17]}$ very well. As mentioned previously, toluene, encircled in Figure 7, is 258 an outlier to this trend. Sasaki et al., ${ }^{[25]}$ also reported low distribution ratios for extraction into 259 both toluene and benzene, and suggested that aromatic compounds might interact with the donor 260 oxygens of the DGA, thus decreasing the activity of the ligand. 
These results justify the use of 1 -octanol as a diluent in the study of REE extraction here, and strongly suggest that the neutral metal complex is the extracted species in this diluent.

\section{Thermodynamics}

The effect of temperature on the $D_{\mathrm{Ln}}$ is shown in the Van't Hoff plot in Figure 8. Linear regression analysis of the plot of natural $\log$ of the distribution ratio versus $1 / \mathrm{T}$ provides a slope

266 that is the negative enthalpy $(-\Delta \mathrm{H})$ divided by the gas constant, $\mathrm{R}$. The Van't Hoff equation is

267 shown below as eq. 3. The resulting enthalpies for $\mathrm{Y}, \mathrm{Sm}, \mathrm{Eu}, \mathrm{Tb}$ and Dy are shown in Table 2.

268 For these REEs extraction from $8.0 \mathrm{M} \mathrm{HCl}$ with TBDGA/1-octanol is exothermic and the

269 stability of the various $\mathrm{Ln}(\mathrm{TBDGA}) n \mathrm{Cl}_{3}$ complexes thus decrease as the temperature increases.

270 Almost no extraction was observed at $65{ }^{\circ} \mathrm{C}$ for all REEs examined. The value obtained here of -

$27142.9 \pm 2.6 \mathrm{~kJ} \mathrm{~mol}^{-1}$ for Dy falls within the range of values reported by Cui et al., ${ }^{[17]}$ using various

272 diluents.

273 Table 2. Enthalpy of reaction of the extraction of rare earth elements with TBDGA.

\begin{tabular}{|l|l|}
\hline Element & Enthalpy of Reaction $\left(\mathrm{kJ} \mathrm{mol}^{-1}\right)$ \\
\hline $\mathrm{Y}$ & $-42.9 \pm 2.6$ \\
\hline $\mathrm{Sm}$ & $-39.9 \pm 2.4$ \\
\hline $\mathrm{Eu}$ & $-39.3 \pm 2.4$ \\
\hline $\mathrm{Tb}$ & $-41.1 \pm 2.5$ \\
\hline $\mathrm{Dy}$ & $-42.9 \pm 2.6$ \\
\hline
\end{tabular}

275 Enthalpy values may vary in different diluents due to a number of factors, including viscosity,

276 ease of solvation of the metal center, and ability to remove water coordinated to the metal center.

$$
\frac{\Delta \ln (D)}{\Delta \frac{1}{T}}=\frac{-H_{t o t}}{R}
$$


It can also be seen by comparing Figure 7 to Table 2 that the extraction efficiency is not

279 strictly related to the enthalpy of reaction. This may indicate that entropy also plays a role in

280 facilitating complex formation. Here, an increase in solvent polarity may enhance TBDGA

281 complexation of the metal through solvation of the water molecules that must be removed from

282 the metal prior to complex formation.

283 Conclusions

Heavy and intermediate lanthanides and yttrium are efficiently extracted from $\mathrm{HCl}$ using millimolar concentrations of TBDGA in 1-octanol. The light lanthanides La and Ce are poorly extracted. For extraction to occur in $\mathrm{HCl}$, at least $3.0 \mathrm{M} \mathrm{HCl}$ is required. However, $\mathrm{H}^{+}$itself negatively impacts the extraction, probably due to competition for the ligand by $\mathrm{HCl}$ extraction which decreases the amount of ligand available for metal ion complexation. When $\left[\mathrm{H}^{+}\right]$was decreased or removed by replacing $\mathrm{HCl}$ with $\mathrm{NaCl}$ to keep the $\mathrm{Cl}^{-}$concentration constant, $D_{\mathrm{Ln}}$ increases. As the $\mathrm{Cl}^{-}$concentration increased, $D_{\mathrm{Ln}}$ also increased due to the metal complex 291 charge neutralization requirement. Although 1 -octanol is a polar diluent, and thus extracts 292 significant amounts of water and acid, significant amounts of metal were not extracted in the 293 absence of the ligand. The L:M stoichiometry for the extracted metal complex measured here is 294 similar to the values reported by others for DGA extractants and thus it was concluded that the 295 neutral complex is still the main extracted metal species in the polar diluent. Lower temperatures 296 are preferred for extraction due to the reaction being exothermic and the $\mathrm{M}(\mathrm{TBDGA})_{n} \mathrm{Cl}_{3}$ 297 complexes therefore being heat labile. Thus, 1 -octanol is a an attractive diluent for REE 298 extraction using TBDGA that provides high extraction efficiency for the intermediate and heavy 299 lanthanides at low ligand concentration, is compatible with the chloride matrix used in industrial 300 REE processing, and does not require extremely acidic conditions to be effective. 
This research was supported by the Critical Materials Institute, an Energy Innovation Hub funded by the U.S. Department of Energy, Office of Energy Efficiency and Renewable Energy, Advanced Manufacturing Office. Work was performed at the Idaho National Laboratory under DOE Idaho Operations Office Contract DE-AC07-05ID14517.

\section{References}

1. Haxel, G. B.; Hedrick, J. B.; Orris, G. J., Rare Earth Elements-Critical Resources for High Technology. USGS, Ed. 2005.

2. Binnemans, K.; Jones, P. T.; Blanpain, B.; Van Gerven, T.; Pontikes, Y., Towards zerowaste valorization of rare-earth-containing industrial process residues: a critical review. $J$. Clean. Prod. 2015, (99), 17.

3. Lian, H.; Hou, Z.; Shang, M.; Geng, D.; Zhang, Y.; Lin, J., Rare earth ions doped phosphors for improving efficiencies of solar cells. Energy 2013, (57), 270.

4. Binnemans, K.; Jones, P. T.; Blanpain, B.; Van Gerven, T.; Yang, Y.; Walton, A.; Buchert, M., Recycling of rare earth: a critical review. J. Clean. Prod. 2013, (57), 270. 5. Gambogi, J., J. Mineral Commodity Summaries - Rare Earths. USGS, Ed. U.S. Geological Survey: 2013; p 128.

6. Kronholm, B.; Anderson, C. G.; Taylor, P. R., A primer on hydrometallurgical rare earth separations. JOM 2013, 65 (10), 1321-1326.

7. Wu, Y.; Yin, X.; Q., Z.; W., W.; Mu, X., The recycling of rare earths form waste tricolor phosphors in fluorescent lamps: a review of processes and technologies. Resour. Conserv. Recycl. 2014, (88), 21-31.

8. Tan, Q.; Li, J.; Zeng, X., Rare earth elements recovery from waste fluorescent lamps: a review. Crit. Rev. Env. Sci. Technol. 2015, (45), 749-776.

9. Tunsu, C.; Ekberg, C.; Foreman, M.; Retegan, T., Studies on the solvent extraction of rare earth metals from fluorescent lamp waste using CYANEX 923. Solvent Extr. Ion Exch. 2014, $650-668$ (650).

10. Innocenzi, V.; De Michelis, I.; Kopacek, B.; Veglio, F., Yttrium recovery from primary and secondary sources: a review of main hydrometallurgical processes. Waste Manage. 2014, (34), 1237-1250.

11. Innocenzi, V.; Ferella, F.; De Michelis, I.; Veglio, F., Treatment of fluid catalytic cracking spent catalysts to recover lanthanum and cerium: comparison between selective precipitation and solvent extraction. J. Ind. Eng. Chem. 2015, (24), 92-97.

12. Das, N.; Das, D., Recovery of rare earth metals through biosorption: an overview. $J$. Rare Earths 2013, (31), 933-943.

13. Murray, A.; Singh, S.; Vavlekas, D.; Tolley, M. R.; Macaskie, L. E., Continuous biocatalytic recovery of neodymium and europium. $R S C A d v$. 2014, (5), 8496-8506. 
14. Santos, V.; Celante, V.; Lelis, M.; Frietas, M., Hydrometallurgical method for recycling rare earth metals, cobalt, nickel, iron, and manganese from negative electrodes of spent Ni-MH mobile phone batteries. Quím. Nova 20134, 37 (22-26), 22.

15. Yoon, H.-S.; Kim, C.-J.; Chung, K. W.; Kim, S.-D.; Kumar, J. R., Recovery process development for the rare earths from permanent magnet scraps leach liquors. J. Braz. Chem. Soc. 2015, 26 (6), 1143-1151.

16. Borra, C. R.; Pontikes, Y.; Binnemans, K.; Van Gerven, T., Leaching of rare earths from bauxite residue (red mud). Miner. Eng. 2015, (76), 20-27.

17. Cui, Y.; Yang, J.; Yang, G.; Xia, G.; Nie, Y.; Sun, G., Effect of diluents on extraction behavior of rare earth elements with $\mathrm{N}, \mathrm{N}, \mathrm{N}^{\prime}, \mathrm{N}^{\prime}$-tetrabutyl-3-oxy-glutaramide from hydrochloric acid. Hydrometallurgy 2012, 121-124, 16-21.

18. Safarbali, R.; Yaftian, M. R.; Zamani, A., Solvent extraction-separation of La(III), $\mathrm{Eu}(\mathrm{III})$, and $\mathrm{Er}(\mathrm{III})$ ions from aqueous chloride medium using carbamoyl-carboxylic acid extractants. J. Rare Earths 2016, (34(1)), 91-98.

19. Yang, J.; Cui, Y.; Sun, G.; Nie, Y.; Xia, G.; Zheng, G., Extraction of Sm(III)and Nd(III) with N,N,N',N'-tetrabutyl-3-oxy-diglycolamidefrom hydrochloric acid. J. Serb. Chem. Soc. 2013, 78 (1), 93-100.

20. Mincher, M. E.; Quach, D. L.; Liao, Y. J.; Mincher, B. J.; Wai, C. M., The partitioning of americium and the lanthanides using tetrabutyldiglycolamide (TBDGA) in octanol and in ionic liquid solution. Solvent Extr. Ion Exch. 2012, 30 (7), 735-747.

21. Mowafy, E. A.; Mohamed, D., Extraction behavior of trivalent lanthanides from nitric acid medium by selected structurally related diglycolamides as novel extractants. Sep. Purif. Technol. 2014, 128, 18-24.

22. Horwitz, E. P.; McAlister, D. R.; Thakkar, A. H., Synergistic enhancement of the extraction of trivalent lanthanides and actinides by tetra-(n-octyl)diglycolamide from chloride media. Solvent Extr. Ion Exch. 2008, 26, 12-24.

23. Ansari, S.A.; Pathak, P.; Mohapatra, P.K.; Manchanda, V.K., Chemistry of diglycolamides: promising extractants for actinide partitioning. Chem. Rev. 2012, 112, 17511771 .

24. Shannon, R. D., Revised Effective Ionic Radii and Systematic Studies of Interatomic Distances in Halides and Chalcogenides. Acta. Chromatogr. 1976, 32 (5), 751-767. 25. Sasaki, Y.; Sugo, Y.; Suzuki, S.; Tachimori, S., The novel extractants, diglycolamides, for the extraction of lanthanides and actinides in $\mathrm{HNO}_{3}$-n-dodecane system. Solvent Extr. Ion Exch. 2001, 19, 91-103.

26. Hofmeister, F., Zur Lehre von der Wirkung der Salze- Zweite Mittheilung. Arch. Exp. Pathol. Pharmakol. 1888, 247-260.

27. Geist, A., Extraction of nitric acid into alcohol:kerosene mixtures. Solvent Extr. Ion Exch. 2010, 28, 596-607.

28. Sasaki, Y.; Sugo, Y.; Morita, K.; Nash, K.L., The effect of alkyl substituents on actinide and lanthanide extraction by diglycolamide compounds. Solvent Extr. Ion Exch. 2015, 33, 625641.

29. Wilden, A.; Modolo, G., Lange, S.; Sadowski, F.; Beele, B.B.; Skerencak-Frech, A.; Panak, P.J.; Iqbal, M.; Verboom, W.; Geist, A.; Bosbach, D. Modified diglycolamides for the An(III)+Ln(III) co-separation: evaluation by solvent extraction and time-resolved laser fluorescence spectrosopy. Solvent Extr. Ion Exch. 2014, 32, 119-137.

30. Smallwood, I.M., Handbook of organic solvent properties. Arnold, London, 1996. 
387

388

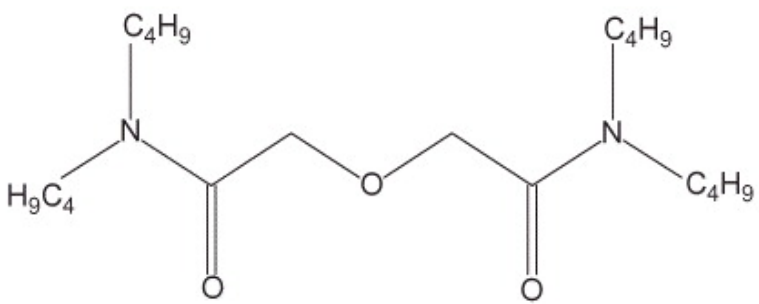

389 Figure 1. Structure of tetrabutyl diglycolamide (TBDGA)

390 


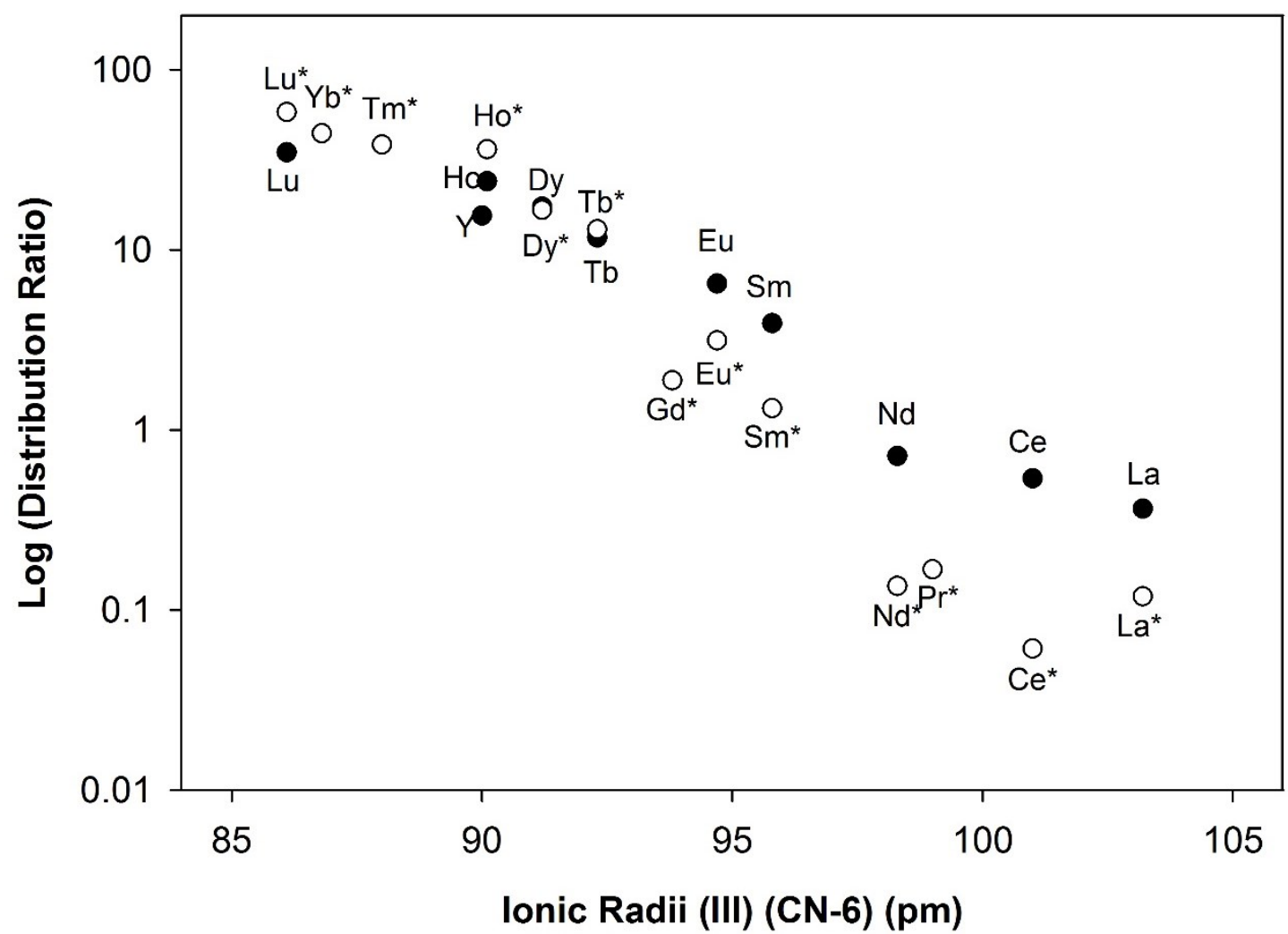

392

Figure 2. Ionic radii (coordination number $=6$ ) versus $\log$ of the distribution ratio for the

394 extraction of REEs using 0.007 M TBDGA in 1-octanol from $8.0 \mathrm{M} \mathrm{HCl}$ (black closed circles)

395 and from $8 \mathrm{M} \mathrm{HNO}_{3}{ }^{[20]}$ (open white circles, labeled with *). 


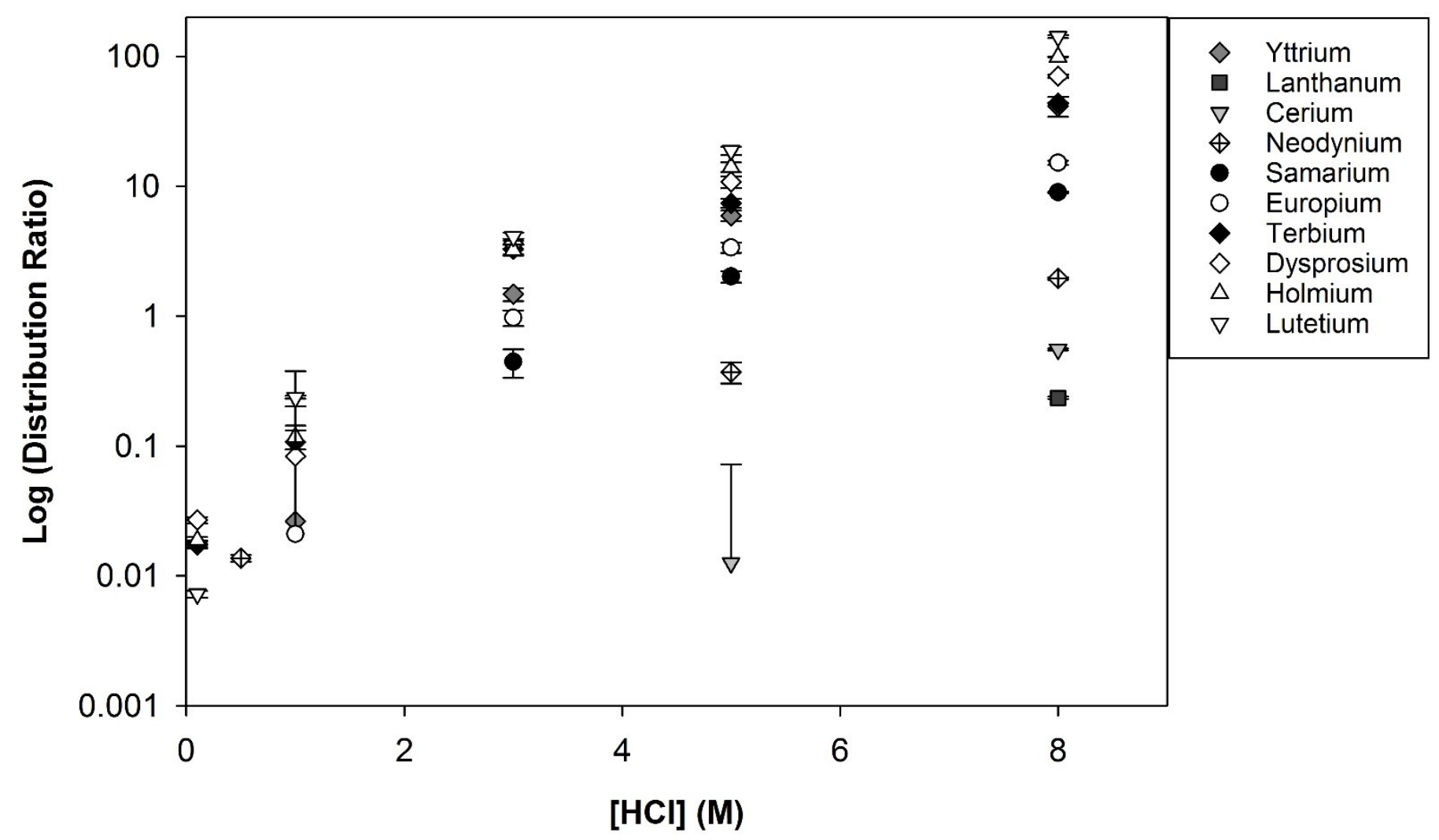

Figure 3. The solvent extraction profiles of $\mathrm{Y}, \mathrm{La}, \mathrm{Ce}, \mathrm{Nd}, \mathrm{Sm}, \mathrm{Eu}, \mathrm{Tb}, \mathrm{Dy}, \mathrm{Ho}$, and Lu from 399 hydrochloric acid media as a function of [HCl] using pre-equilibrated 0.010 M TBDGA in 1400 octanol. The aqueous phase consisted of $\sim 100 \mathrm{ppb}$ of each REE resulting in a total REE 401 concentration of about $7 \mu \mathrm{M}$. 


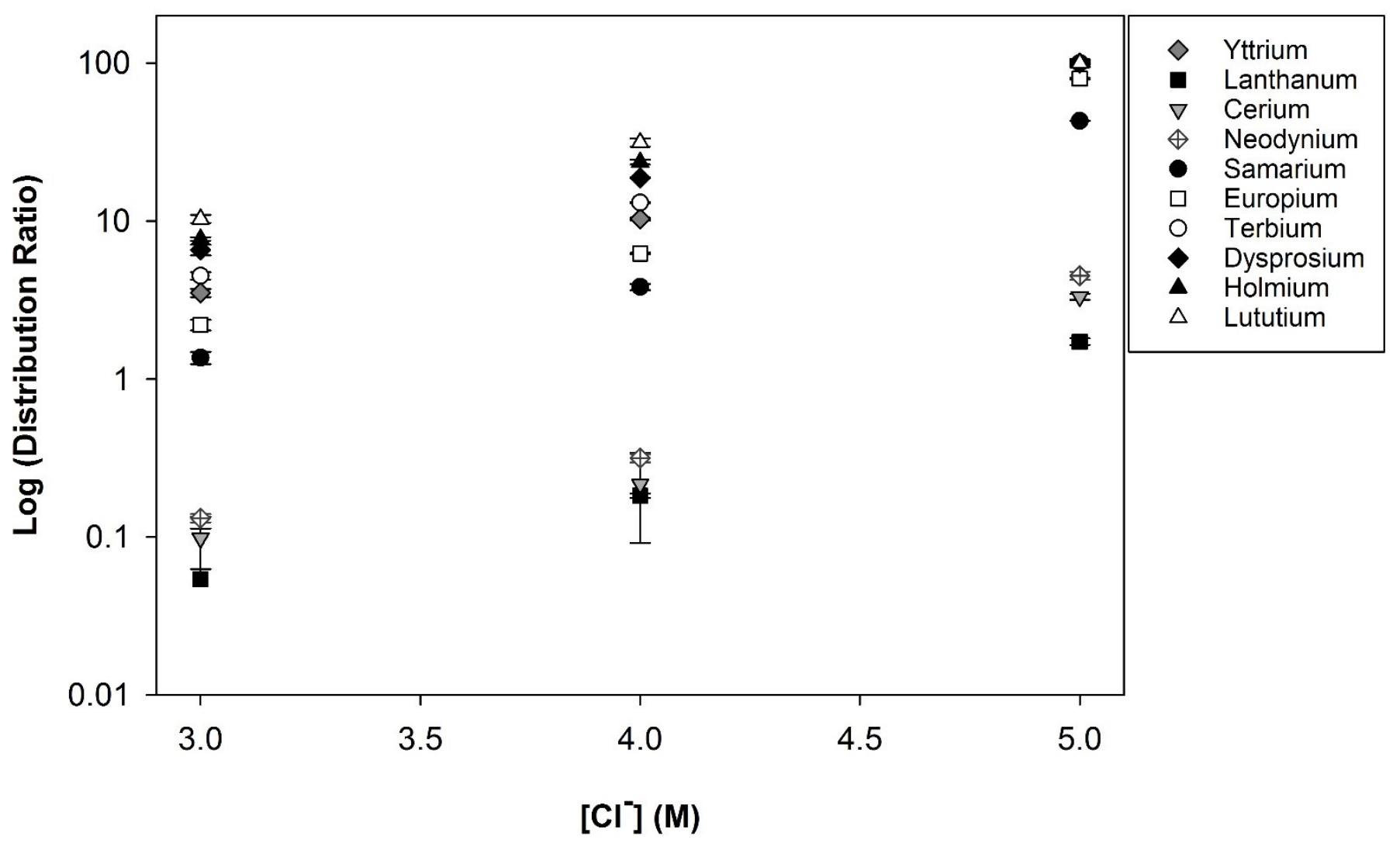

404 Figure 4. The solvent extraction profile of Y, La, Ce, Nd, Sm, Eu, Tb, Dy, Ho, and Lu from

405 aqueous media with $1.0 \mathrm{M} \mathrm{HCl}$ and 2.0 $\mathrm{M}-4.0 \mathrm{M}$ added $\mathrm{NaCl}$ using pre-equilibrated $10 \mathrm{mM}$

406 TBDGA in 1-octanol. The aqueous phase consisted of $\sim 100 \mathrm{ppb}$ of each REE resulting in a total

407 REE concentration of about $7 \mu \mathrm{M}$.

408

409 


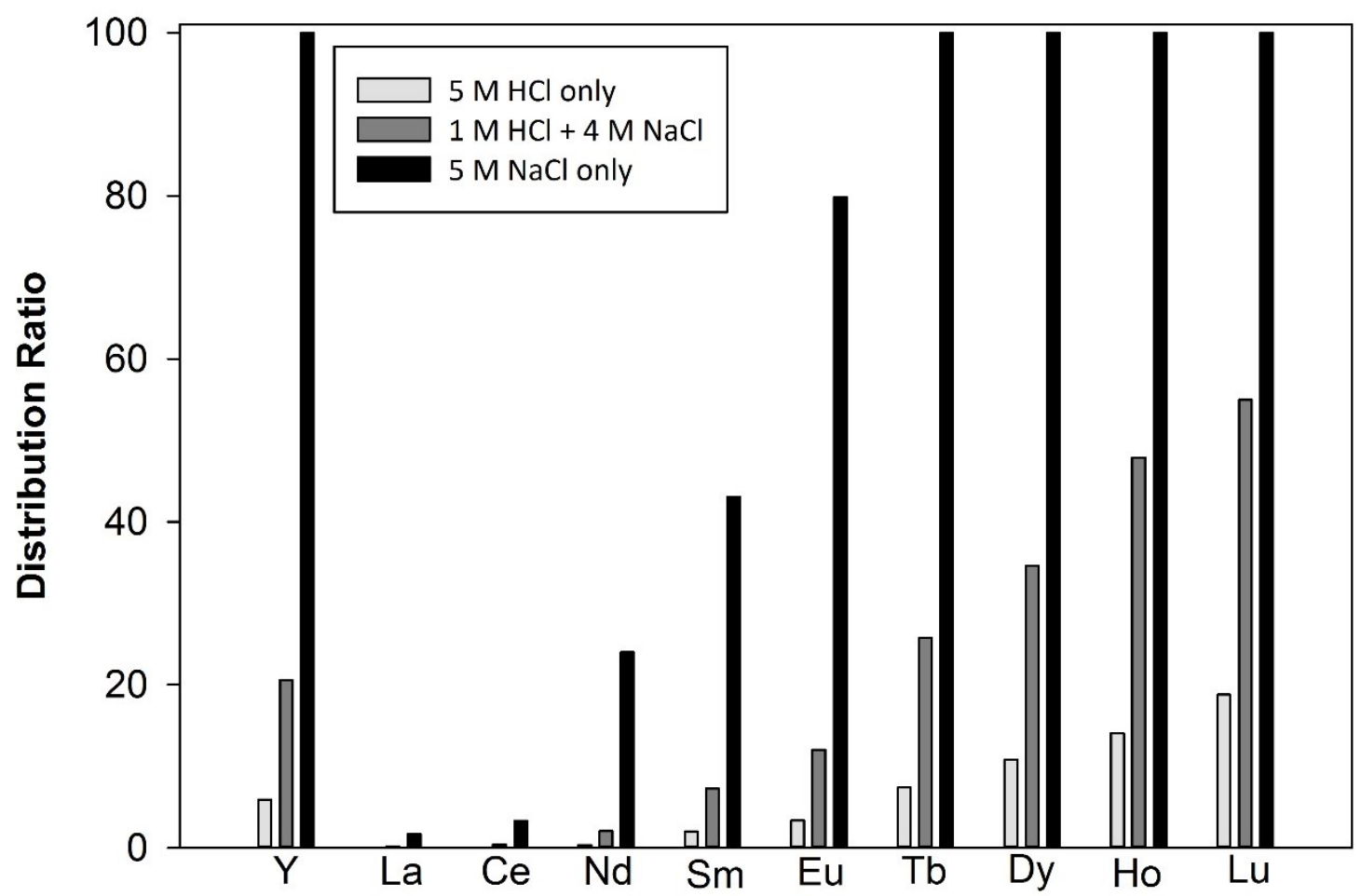

411 Figure 5. Distribution ratios for extraction of REEs from 5.0 $\mathrm{M} \mathrm{Cl}^{-}$solutions of varying acidity.

412 Pre-equilibrated $10 \mathrm{mM}$ TBDGA in 1-octanol was contacted with an aqueous phase containing $413 \mathrm{Y}, \mathrm{La}, \mathrm{Ce}, \mathrm{Nd}, \mathrm{Sm}, \mathrm{Eu}, \mathrm{Tb}, \mathrm{Dy}, \mathrm{Ho}$, and Lu with a total REE concentration of about $7 \mu \mathrm{M}$. The 414 light grey bars shows $5.0 \mathrm{M} \mathrm{HCl}$, the dark grey shows $1.0 \mathrm{M} \mathrm{HCl}+4.0 \mathrm{M} \mathrm{NaCl}$, and the black 415 bars shows $5.0 \mathrm{M} \mathrm{NaCl}$. 


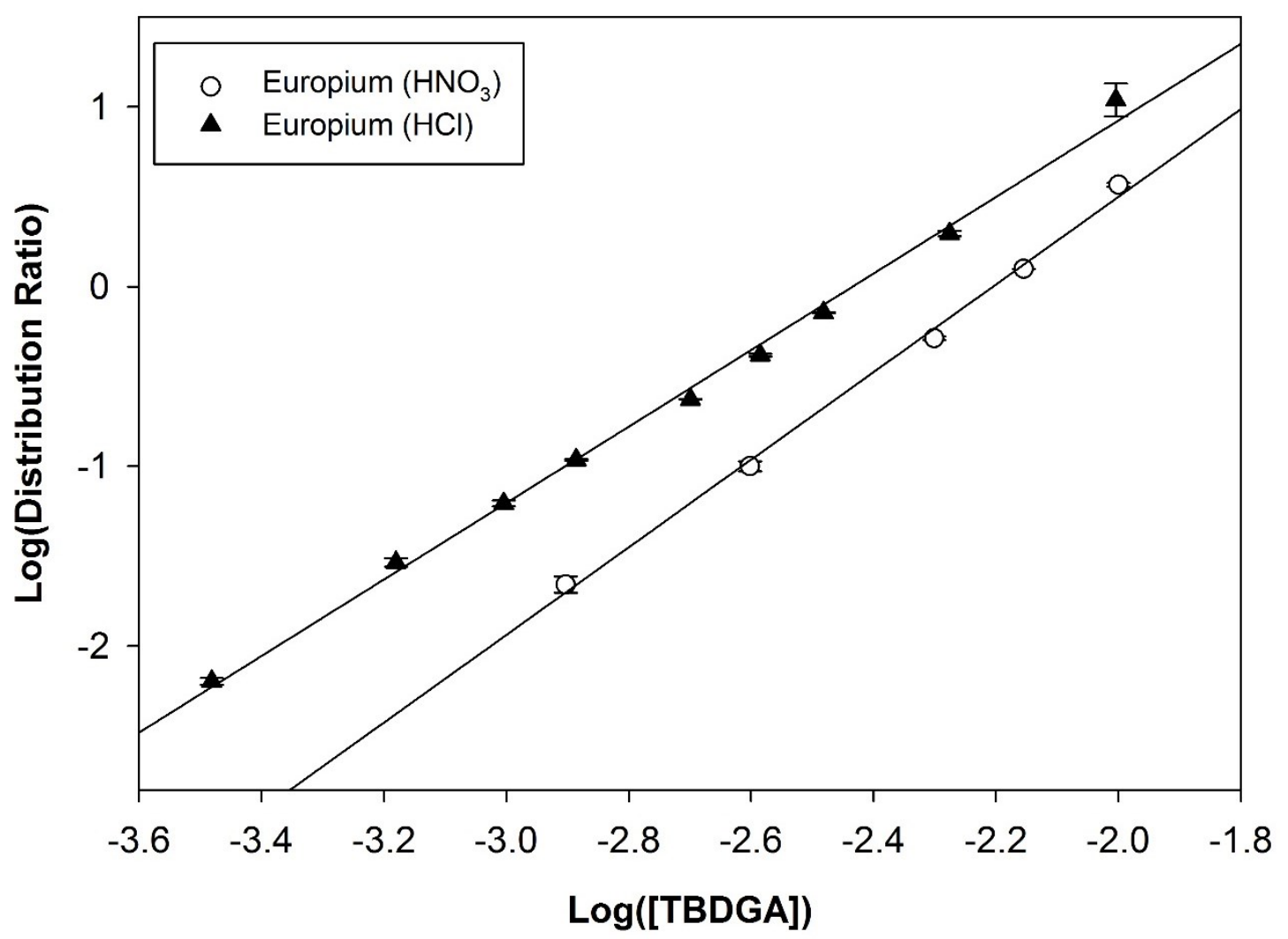

416

417

418

419 Figure 6. Log of the distribution ratio versus $\log [$ TBDGA], for the determination of the L:M

420 stoichiometry for Eu extraction from $\mathrm{HCl}$. The Eu concentration was $110 \mathrm{ppb}$ in $8.0 \mathrm{M} \mathrm{HCl}$ with

421 a contact time of 15 minutes (open circle). Similar data from reference [20] are shown for $\mathrm{HNO}_{3}$

422 (black triangle).

423

424 


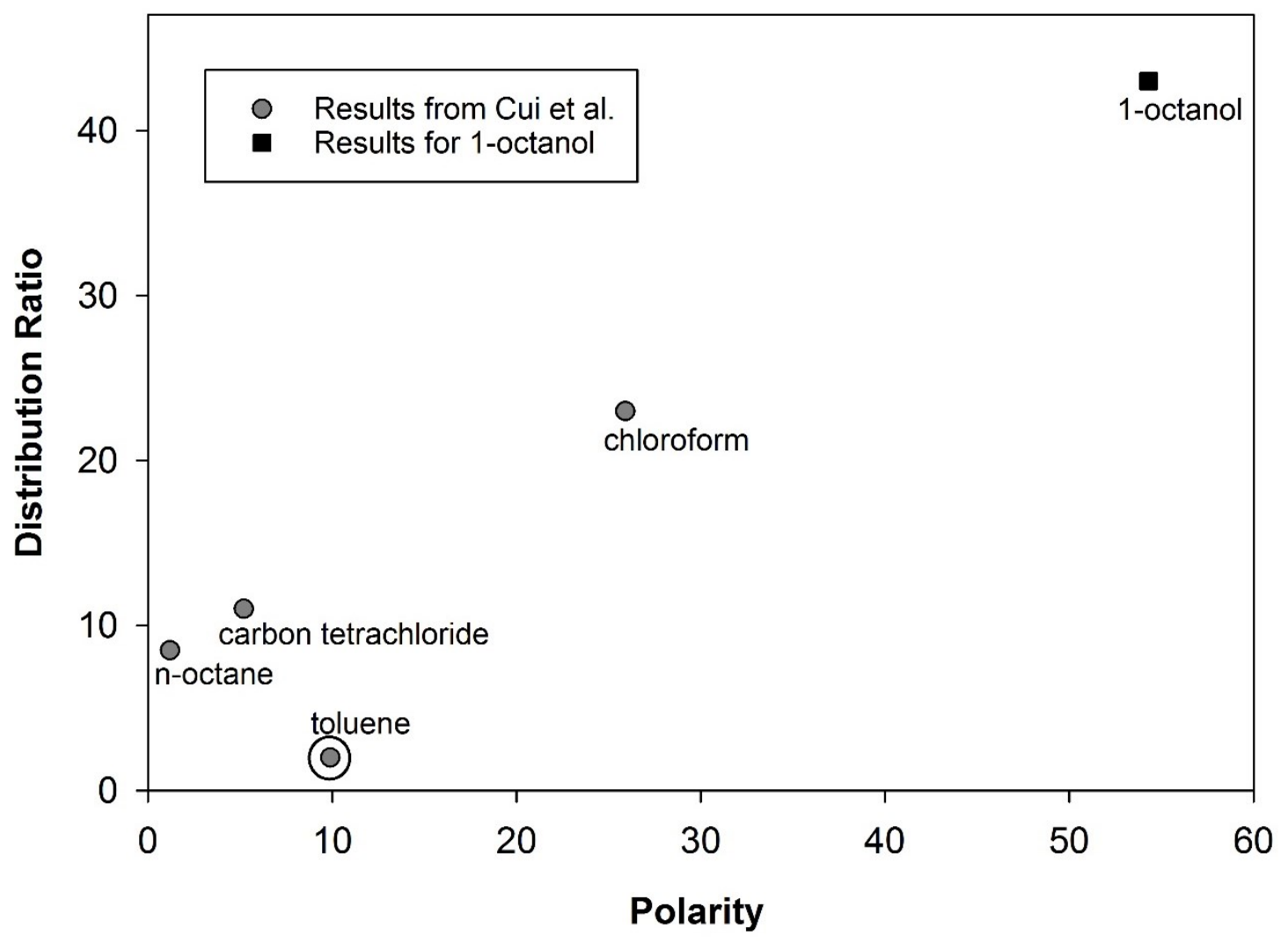

427 Figure 7. Distribution ratios for extraction of $\mathrm{Dy}$ from $\mathrm{HCl}$ using various TBDGA in various

428 diluents as reported by Cui et al. $\left(\left[\mathrm{Dy}^{3+}\right]=4.00 \times 10^{-3} \mathrm{M},[\mathrm{TBDGA}]=0.20 \mathrm{M},[\mathrm{HCl}]=5 \mathrm{M}\right),{ }^{[17]}$

429 compared to the results for extraction into 1-octanol of this study versus the polarity index of the 430 diluent $($ water $=100){ }^{[30]}$ 


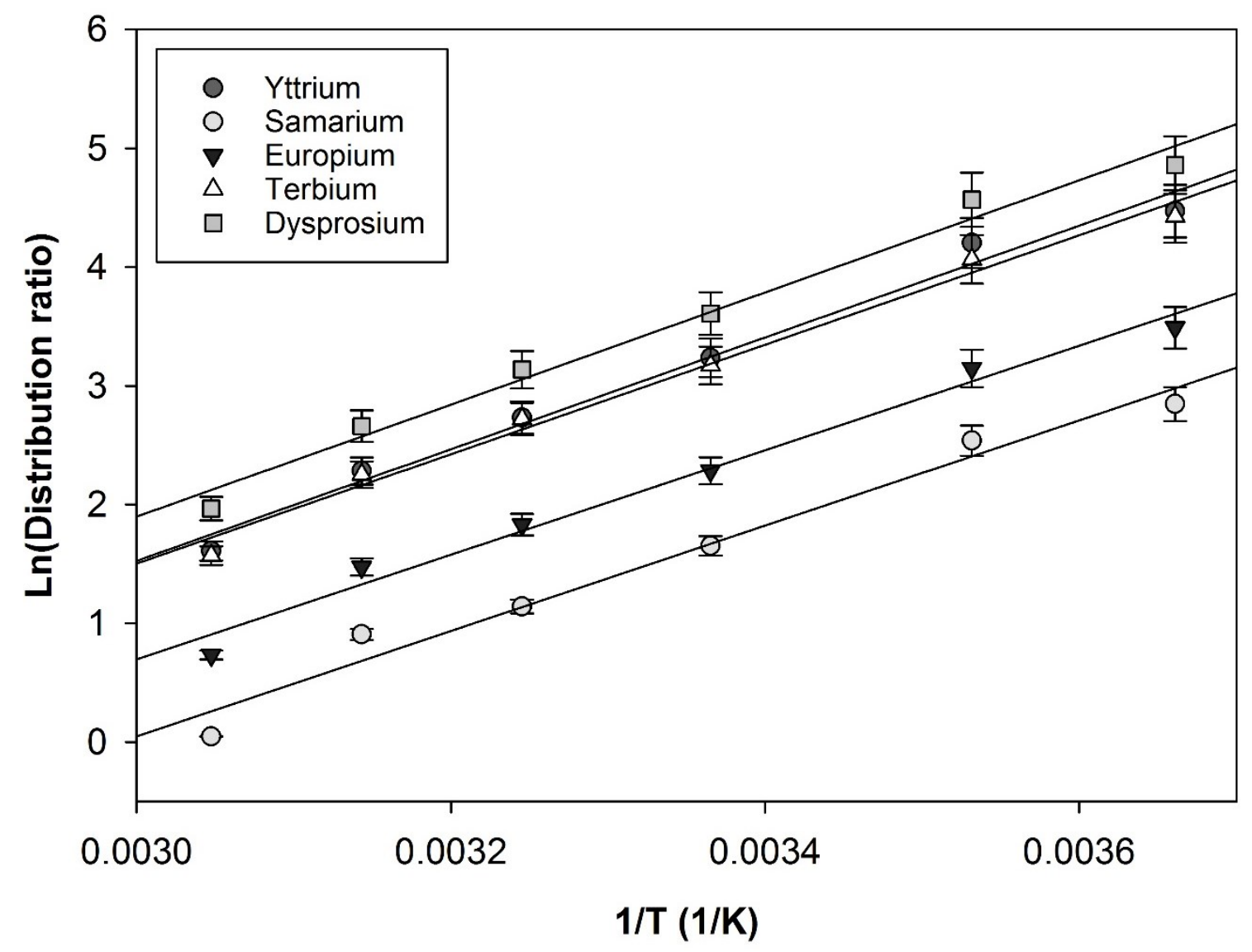

432 Figure 8. Effect of temperature on the extraction of several REEs from $8.0 \mathrm{M} \mathrm{HCl}$ with $0.010 \mathrm{M}$ 433 TBDGA in 1 -octanol. 
434

435 